\title{
Reflections on the Specialty Construction of Information Countermeasure Technology in Local Colleges and Universities under the Background of New Engineering
}

\author{
- Taking Xi'an Technological University as an Example
}

\author{
Ya-wen WANG * \\ School of Computer Science and Engineering \\ Xi’an Technological University \\ Xi'an, China
}

\author{
Zhi-ping Liu, Xiu-hua Hu, Jun Yu \\ School of Computer Science and Engineering \\ Xi’an Technological University \\ Xi'an, China
}

\begin{abstract}
In order to make the specialty construction of information countermeasure technology meet the requirements of new engineering, this paper expounded the problems and difficulties existing in the information countermeasure technology specialty of local colleges in the construction of new engineering from four aspects: talent training system, teachers troop, experimental conditions and management system. And some measures to solve the problems was put forward in this paper, such as talent training system construction, teachers troop construction, experimental condition improvement and college management system reform. Under the background of new engineering, it needs the joint efforts of colleges, teachers, students and enterprises to achieve substantial results.
\end{abstract}

Keywords-New Engineering; Information Countermeasure Technology; Talent Training; Teachers Troop; Experimental Conditions

\section{INTRODUCTION}

2017 is a crucial year for China's new engineering construction. "New engineering" construction Fudan consensus[1], "new engineering" construction action route ("Tianjin University Action")[2], new engineering construction guide (" Beijing Guide ")[3] have been published successively. They pointed out the direction for China's new engineering construction. In particular, the "Beijing Guide" explicitly puts forward the guiding opinions on the construction of new engineering, according to different situations of various colleges and universities across the country, classified development is carried out. That is to say, engineering advantage universities should play a main role in engineering technological innovation and industrial innovation, comprehensive universities should play a leading role in promoting new technologies and incubating new industries, local universities should play a supporting role in regional economic development and industrial transformation and upgrading. Through these measures, we will achieve the goal of cultivating different types of outstanding engineering talents

Fund Program: First-class specialty training project of Shaanxi University "First-class specialty construction of information countermeasure technology" (undergraduate section NO.295); Teaching reform research project of Xi'an Technological University (19JGY22) and comprehensively improve the quality of engineering education[4].

As a local college, in the construction of new engineering the information countermeasure technology specialty of Xi'an Technological University should base on our own characteristics and advantages. We will cultivate specialized personnel in information security for local governments and enterprises, and promote the development of local economy and the transformation and upgrading of information security industry[5]. However, there are many problems and difficulties in the construction of new engineering in our university's information countermeasure technology specialty. This paper tries to expound these problems and give some measures to solve them.

\section{The BASIC EsSENTIALS OF NEW ENGINEERING CONSTRUCTION}

\section{A. The connotation and significance of new engineering construction}

The connotation of the new engineering is: to foster people by virtue, to cope with changes and shape the future as the construction concept, to inherit and innovate, cross and integrate, coordinate and share as the main way, to cultivate the innovative and outstanding engineering talents[6].

The new engineering construction is to meet the challenge of new economy. From the height of serving national strategy, meeting industrial demand and facing future development, and on the basis of "excellent engineer education and training plan" (hereinafter referred to as "excellent plan"), the nation has put forward a major action plan to continuously deepen the reform of engineering education[7].

China is implementing an innovation-driven development strategy and a series of major development strategies, including "made in China 2025", "Internet plus", "National cyber development strategy" and "One Belt And One Road"[8-11]. It is of great practical and strategic significance to cultivate engineering and scientific talents with a strong scientific 
foundation, strong engineering ability and high comprehensive quality to support and serve the new economic development characterized by new technologies, new forms of business, new industries and new models. And it is also an important prerequisite for building a strong manufacturing country and an innovative country[12].

\section{B. The main objective of new engineering construction}

In the matter of the great mission that engineering discipline should undertake for national economic and social development, the construction and development of new engineering should focus on the construction of new engineering majors and its personnel training. In this sense, the main goal of new engineering construction can be expressed as: actively laying out, setting up and building engineering disciplines and majors that serve the national strategy, meet the industrial demand and face the future development; cultivating a group of interdisciplinary outstanding engineering and technology talents with innovation and entrepreneurship ability, cross-border integration ability and high quality[13].

\section{PROBlems In The Construction OF NeW ENGINEERING}

\section{A. There is a gap between the talent training system and the} requirements of new engineering construction

There are the following problems in the training system of information countermeasure technology specialty in local universities. On the goal of talent training, students are emphasized to solve practical problems with their specialized knowledge, and they despise the education of the humanistic and social science literacy and social responsibility. There are many specialized basic courses, specialized courses, specialty-oriented or industrial application courses in the specialized curriculum system, and there are few courses in project management and innovation and entrepreneurship. In the talent training mode, curriculum-based learning is emphasized, project-based learning, personalized learning and international joint talent training are not enough.

\section{B. Existing faculty cannot meet the needs of new engineering construction}

There are eight teachers in the information countermeasure technology specialty of Xi'an Technological University. Among them, two teachers got doctorates, one teacher are doctoral student; five teachers got master's degree. There are few teachers with doctorates. Fewer than 50 percent of the teachers have a background in information security-related subjects. Specialized related research projects which are directed or participated in by the teachers in this specialty are few. Since almost all teachers in this specialty have studied or worked in the school for a long time, there are fewer opportunities for them to practice in enterprises, so the practical ability of the teachers in this specialty is poor, which affects the cultivation of students' practical ability[14].

\section{The experimental conditions are not enough to support the cultivation of students' practical ability}

There are two laboratories in the information countermeasure technology specialty of our university now,they are the blue shield information security laboratory and the hongyaa network attack and defense countermeasure training base. The two laboratories can do some basic experiments. However, the experimental content is old, and the experiment of the latest technology cannot be realized, which is not good for students to master the latest network attack and defense and information security technology. Most of the experiments are limited to validation experiments, and designed experiments and comprehensive experiments are few. At present, students are only allowed to complete experiments in the laboratory, they cannot conduct experiments remotely, and the experiment is limited by space.

\section{The management system cannot meet the needs of new engineering construction}

In the personnel assessment system, the reward for scientific research is large, while the reward for teaching is relatively small. The number and grade of papers are too high in title evaluation, and there is not much room for promotion for teacher-centered teachers. As a result, teachers prefer to focus too much on scientific research and less on teaching.

\section{TARGETED SOLUTIONS}

\section{A. Personnel training system construction}

We will strengthen research on personnel training objectives. We must determine the personnel training objectives that are consistent with the development of The Times, the needs of enterprises, the education certification of engineering and the characteristics of our university. Students are trained to solve complex engineering problems, to have innovative consciousness, humanistic and social science literacy and social responsibility, to understand and master engineering management principles and economic decision-making methods, and to achieve cross-cultural communication.

We need to optimize and improve the specialized curriculum system, add project management courses and innovation and entrepreneurship courses, and carry out corresponding practical teaching for these courses.

We need carry out research and reform on the talent training model, carry out project-based learning, teaching based on MOOC/SPOC, international double degree joint training, school-enterprise joint talent training and other personnel training, and further improve the quality of talent training.

\section{B. Teaching staff construction}

The goal of the teaching staff construction in information countermeasure technology specialty is to build a high-quality teachers troop that is consistent with the specialty development. It can be achieved mainly through two ways that are the introduction of talents and self-cultivation.

The specific measures for teaching staff construction include the introduction of outstanding $\mathrm{PhD}$ graduates from relevant specialties, inviting famous professors who work on related fields from our country or foreign country to guide the specialty construction, encouraging teachers who are on the job to study for one's doctorate in related fields, supporting teachers to attend relevant training or courses, encouraging 
teachers as visiting scholars to go to high-level universities at home and abroad, appointing teachers to work in information security enterprises, encouraging teachers to apply for projects related to information countermeasure technology specialty, and so on.

\section{Improvement of experimental conditions}

The improvement of experimental conditions mainly depends on the construction of the laboratory's basic conditions, the construction of off-campus practice bases, and the participation of students in teachers' research projects, and so on.

The university should carry out timely upgrading of laboratory equipment and optimization of experimental courses, and strive to introduce the latest technology into the laboratory. Design experiments, comprehensive experiments, research experiments and open experiments should be set up to make up for the deficiency of basic experiments and verification experiments. Remote laboratories should be opened so that students can do experiments outside the laboratory.

Taking these policies as an opportunity, such as the industry and education cooperation project of the Ministry of Education, the construction of off-campus innovation and entrepreneurship practice education base for college students in Shaanxi province. We will establish a number of off-campus practice bases for information countermeasure technology specialty and expand the space of practical teaching.

We encourage students to take an active part in the research project related to teachers' specialty, make full use of the experimental conditions and training opportunities provided by teachers' programs, get the same internship opportunities as those provided by outside companies, and improve students' abilities.

\section{Reform of university management system}

The university management system should incline to the teaching work, which will certainly arouse the enthusiasm of teachers. In terms of the personnel assessment system, teaching scores and proportion should be increased, so that teaching and scientific research have equal status. In the professional title evaluation system, special channels should be set up for a teacher who teaches well. For example, teaching teachers' professional title evaluation conditions, so that teaching teacher can assess the corresponding professional title.

\section{CONCLUSION}

The construction of new engineering has pointed out the direction of efforts for the training of information countermeasure technology specialty in local universities, and higher requirements have also been raised. It is a historical mission given by The Times to cultivate innovative talents with sustainable competitiveness in information countermeasure technology specialty.The construction of information countermeasure technology specialty requires the joint efforts of schools, teachers, students and enterprises to achieve substantial results.

\section{REFERENCES}

[1] Fudan consensus on "new engineering" construction [EB/OL] http://www.moe.edu.cn/s78/A08/moe_745/201702/t20170223_297122.h tml.(In Chinese)

[2] "New engineering" construction action line("Tianjin University Action") [EB/OL].

http://www.moe.edu.cn/s78/A08/moe 745/201704/t20170412 302427.h tml. ( In Chinese)

[3] Guide to new engineering construction ("Beijing Guide") [EB/OL] http://tmxy.stdu.edu.cn/tumupinggu/2679-2017-11-10-08-51-24.html. (In Chinese)

[4] Xia Jianguo, Zhao Jun. "Discussion on the reform and development of engineering education in local universities under the background of new engineering construction”. Research on higher engineering education, vol.2017, pp.15-20, March 2017. (In Chinese)

[5] Wang Yawen, Yu Jun, Liu Zhiping. "Practice of the personnel training mode for information countermeasure technology professional based on discipline competition platform”. Laboratory research and exploration, vol.37, pp.223-225, March 2018. (In Chinese)

[6] Zhong Denghua. "Connotations and Actions for Establishing the Emerging Engineering Education”. Research in Higher Education of Engineering, vol.2017, pp.1-6, March 2017. ( In Chinese)

[7] Lin Jian. "New engineering construction leading higher education reform”. China Higher Education, vol.2017, pp.40-43, July 2017. (In Chinese)

[8] The state council circular on the issuance of made in China 2025[EB/OL].

http://www.gov.cn/zhengce/content/2015-05/19/content 9784.htm. (In Chinese)

[9] Guidance from the state council on actively promoting the "Internet plus" initiative [EB/OL]

http://www.gov.cn/zhengce/content/2015-07/04/content_10002.htm. ( In Chinese)

[10] The great significance and practical requirement of network power strategy thought $[\mathrm{EB} / \mathrm{OL}]$.

http://theory.people.com.cn/n1/2018/0912/c40531-30287646.html. (In Chinese)

[11] Authorized release: vision and actions on jointly building the silk road economic belt and the 21st century maritime silk road[EB/OL]. http://world.people.com.cn/n/2015/0328/c1002-26764633.html. (In Chinese)

[12] Lu Guodong. "Five breakthroughs and preliminary exploration in the construction of "new engineering". China University Teaching, vol.2017, pp.38-41, May 2017. ( In Chinese)

[13] Lin Jian. “The Construction of China's New Engineering Disciplines for the Future”. TSINGHUA JOURNAL OF EDUCATION, vol.38, pp.26-35, March 2017. (In Chinese)

[14] Ye Jin, Huang Bing, Zhang Xiangli, et al. "Construct for Information Countermeasure Technique Specialty”. JOURNAL OF EEE, vol.32, pp.14-15, March 2010. (In Chinese) 